\title{
Are superordinates such as furniture and belongings collective nouns?
}

\author{
Laure Gardelle \\ Université Grenoble Alpes
}

author accepted manuscript

This paper has been accepted for publication in a journal, is under copyright, and the publisher should be contacted for permission to re-use the material in any form. doi.org/10.1075/li.00002.gar

\begin{abstract}
One area of debate as to the boundaries of the class of "collective nouns" concerns non-count singular nouns such as furniture, which are typically used for several units of different kinds. Arguments for and against inclusion have been put forward, but ultimately, what has been noted is a number of similarities and differences compared with count collective nouns. This makes both positions as legitimate, especially as collective nouns are a partly heterogeneous class (e.g. only those denoting humans, or sometimes animals, license plural override: the committee were... vs. *the bouquet were...). The present paper addresses the issue from a different angle, comparing furniture nouns not just with other singular nouns (whether collective or superordinate), but with count nouns in the plural (e.g. toys). This new angle enables us to propose that furniture nouns are superordinate hyperonyms of plural, rather than singular, categories. This notion accounts for all the similarities and differences noted between furniture nouns and count collective nouns, and leads to the conclusion that furniture nouns are clearly not collective nouns. The analysis is then extended to non-count plural nouns that denote units (e.g. belongings), which have been neglected, or sometimes rejected on arbitrary grounds. The present study shows that they are not collective nouns either, and that they, too, are superordinates, some of them hyperonyms of plural categories.
\end{abstract}

\section{Introduction}

At first sight, collective nouns (e.g. archipelago, committee) are an easy category to define. Collective, from the Latin collectivus, signifies "formed by collection of individual persons or things" (OED, entry collective); consequently, a typical definition of a collective noun is "a substantive which (in the singular) denotes a collection or number of individuals" (OED). From this, existing studies agree in defining a collective noun as being characterised by a discrepancy between a singular morphology and a capacity to refer to a plurality (e.g. Flaux 1999, Flaux \& Van de Velde 2000, Arigne 2005, Joosten et al. 2007, Joosten 2010, Lammert $2010^{i}$ ). This feature has been retained by grammarians for centuries, for instance by Kirkby (1746, p. 65) in the $18^{\text {th }}$ century: "Names which have the Ending of Singulars and Meaning of Plurals are called Collectives: as an Army, Brace, Company."

Closer to us, various authors have shown that the category of collective nouns is in fact not that simple to circumscribe. Firstly, collectiveness is partly a matter of conceptualisation (Wierzbicka 1988, pp. 517-519). For instance, although rice is made up of grains, it is not construed as a collection of such grains, because a grain is usually not of special interest. The relation between rice and grain is therefore not collection / member, but substance / particle. Secondly, the category of collective nouns is heterogeneous. Collectiveness is sometimes just

\footnotetext{
${ }^{i}$ Flaux, Van de Velde and Lammert work on collective nouns in French, but their work is included in the references because collective nouns in French share many characteristics with those in English, so that their arguments are fully relevant to the present study.
} 
a facet ${ }^{\mathrm{ii}}$ of the meaning of the noun (Lammert, 2010, p. 319). For instance, while herd is always collective, village takes on a collective meaning only by metonymy ("the people in the village", as in All the village knew that...). Collective nouns may also differ partly in their grammatical behaviour. In English, for example, only nouns referring to groups of people, and sometimes to animals, can take singular or plural agreement (e.g. the committee was/were informed..., vs. * the bouquet were...). Even among these, there are different degrees of what Joosten et al. (2007) call "permeability", that is, of access to the members of the collection. For instance, in a young government, young applies to the collective whole and not to the members, whereas in a young couple, it applies to the members. In that sense, couple is more permeable than government. Similarly, Huddleston \& Pullum (2002, p. 1501) note that to many speakers, One couple clearly hated each other's guts "seems better" than The government didn't like each other much.

One area of debate, which will be the focus of the present paper, regards singular noncount nouns such as furniture or jewelry, which in discourse usually refer to sets of heterogeneous units. Although they are non-count nouns, they differ from other non-count nouns such as water in that they do not imply arbitrary divisibility: while any amount of water is water, furniture chopped to pieces would not be just "furniture" (but broken furniture) (Wierzbicka, 1988, p. 511, Huddleston \& Pullum, 2002, p. 336). Instead, as for count collective nouns such as committee or archipelago, the elements referred to are a collection of units, that is, of discrete components. Linguists therefore diverge as to the semantic classification of these nouns. Among grammarians, Greenbaum (1996, p. 456) cites cutlery and confectionery as examples of collective nouns; conversely, Huddleston \& Pullum (2002, p. 504) term them "non-count nouns that denote aggregates of heterogeneous entities". In specific studies, Arigne (2011) and Lammert (2010) propose to include these nouns among collective nouns, and Wierzbicka (1988, p. 513) terms them nouns that denote "collective supercategories". Flaux (1999) and Flaux \& Van de Velde (2000), on the other hand, reject them because they aim for a category that correlates meaning (collection) and grammatical form (count nouns) - but they still call them nouns that denote "open collections", hence oddly denying nouns that denote collections the status of collective nouns. Finally, Joosten (2010) argues for a distinction between collections (denoted by count nouns), superordinates (e.g. flower) and aggregates (understood as singular non-count nouns such as furniture ${ }^{\mathrm{iii}}$ ). However, he concludes that his distinction does not allow for a clear classification of nouns such as forest, which can be both count and non-count. In another paper (2006), he also calls for studies devoted to non-count plurals such as belongings, which, too, usually denote sets of discrete entities in context and are superordinates. In most studies, these nouns are not mentioned at all, probably because they do not offer a contrast between a singular form and a plural meaning. But Lammert, who at first explicitly rejects French non-count plurals from collective nouns on those grounds $(2010$, p. 68, p. 465), later on concludes that this lack of contrast may in fact not be a necessary criterion $(2015$, p. 75$)$, as the plural is still lexical in nature (rather than just grammatical or morphological as in the case of count nouns), and as many French plural-only nouns originate in Latin neuters called "collective" in the literature.

The present paper takes the debate from here, with the following question: are singular non-count nouns such as furniture, and/or plural non-count nouns such as belongings,

\footnotetext{
ii As defined by Cruse (1995, p. 44): "a discrete component of a single sense".

iii Joosten's notion of "aggregate" differs from that of Jackendoff (1991), who distinguishes between four types of material entities:

- individuals: [+ bounded] [-internal structure] e.g. a teapot

- groups: [+ bounded] [+internal structure] e.g. a committee

- substances: [- bounded] [-internal structure] e.g. mud

- aggregates: [- bounded] [+internal structure] e.g. buses, committees

Some aggregates have an inherent shape (e.g. piles), others do not (e.g. groups) (Jackendoff, 2012, p. 1141).
} 
collective nouns? This question is addressed from a new angle: rather than compare these nouns with other singular nouns, as existing studies do (whether with singular count collective nouns like archipelago, or taxonomic superordinates such as vehicle), the claim made here is that they should also be compared with count nouns in the plural (henceforth called "plural count nouns" - also known as "bare plurals"), as suggested by Jackendoff (1991)'s classification of nouns of material entities (see footnote iii). Among these plural count nouns, too, superordinates are to be found, and what is more, some of them are most frequently used in the plural in everyday discourse, even though they exist in the singular (e.g. appliances, accessories). Plural count nouns, it is claimed here, are the key to understanding the true relations between furniture and its hyponym chair(s), as well as the co-existence of nouns such as count jewel(s) and non-count jewelry. True, plural count nouns differ from furniture or belongings in that they are count, so that their number feature is assigned in discourse and at phrasal level (via a NumP in the DP, in generative frameworks); whereas for furniture and belongings, number is a lexical feature of the noun (Corbett, 2006, p. 130). But the comparison is still relevant, and as will be shown, the plural of count nouns may be more than a feature selected in discourse (see especially figure (d) in 2.4 below).

In order to address these issues, section 1 first reviews the arguments for and against the inclusion of nouns such as furniture (non-count singular nouns typically denoting a plurality of units) or belongings (non-count plural nouns denoting a plurality of units ${ }^{\text {iv }}$ ) among collective nouns. For practical purposes, at this stage these nouns will be called "furniture nouns" and "belongings nouns". Section 2 then proposes a theoretical model based on plural categories, which leads to the conclusion that furniture nouns and belongings nouns are definitely not collective nouns, despite the partial similarities with words such as committee or archipelago.

\section{Review of existing arguments for and against the inclusion of furniture / belongings among collective nouns}

Joosten (2010) is the only study, to our knowledge, which is devoted to the distinctions between furniture nouns and count collective nouns. This section will therefore consider his five arguments against inclusion of furniture nouns among collectives, and possible objections to them. As for belongings nouns, only Acquaviva (2008) and Lammert (2015) propose arguments against inclusion that go beyond the lack of discrepancy in number between morphology and meaning. Their arguments, which in some ways are close to Joosten's approach to furniture nouns, will be included in section 1.1.

Joosten (2010)'s argumentation rests on a threefold distinction between:

- collective nouns (count): e.g. archipelago

- aggregate nouns (non-count): e.g. furniture

- superordinate nouns (count only): e.g. vehicle.

This distinction leads Joosten to establish a number of important differences between (count) collective nouns and aggregate nouns. The rest of this section considers these differences in turn.

\subsection{Count vs. non-count nouns}

\footnotetext{
${ }^{\text {iv }}$ Consequently, not all nouns in -ings are considered here. For instance, the study excludes sweepings, as the elements that compose the whole are not units, as defined by the OED: " 2 . A single individual or thing regarded as a member of a group or number of things or individuals, or discriminated from these as having a separate existence; one of the separate parts or members of which a complex whole or aggregate is composed or into which it may be analysed." In the case of sweepings, each individual bit seems to be construed as a particle rather than as an element with a "separate existence".
} 
Joosten (2010, p. 44), following Bache (2002), considers that an ideal metalinguistic category is one that correlates meaning and form. To him, therefore, different grammatical features (count vs. non-count) point to different categories. Lammert (2010, p. 191), however, aptly objects that some collective nouns, such as forest or family, can be either count or non-count depending on the context.

To Jackendoff (1991) and Joosten (2010, p. 44), another difference, related to this grammatical distinction, is one of conceptualisation: a count collective noun, being a count noun, denotes a bounded whole, a whole that is conceptualised as a unit, whereas this is not true of furniture nouns. While acknowledging this difference, Lammert (2010, p. 184) argues that in context, furniture nouns can refer to bounded wholes as well - for instance, my livingroom furniture refers to the set of items of furniture in my living-room.

About belongings nouns, Acquaviva (2008, p. 104) puts forward the same objection as Jackendoff (1991) and Joosten (2010): the units are bound together by a cohesive relation, but no property can be ascribed to the group as a single entity. For instance, old belongings means that each item is old. In this respect, these nouns are similar to plural NPs ${ }^{\mathrm{v}}$, such as the heirs: a plural NP licenses a non-distributive predicate (e.g. the heirs met), but the heirs shrank in size can only mean that each heir shrank, not that the group of heirs diminished (for instance if one of the heirs died). Lammert (2015, p. 80) points to another potential conceptual difference: two French non-count plurals at least, déchets ('rubbish') and vivres ('victuals'), unlike collective nouns, do not license meronymic glosses in generic contexts. For instance, Les déchets se composent de mégots, de bouteilles vides, ... ('(The) rubbish is composed of cigarette ends, empty bottles, ...') will only have a specific reading; and the phrase font partie $d e$ ('are part of'), which signals a meronymic relation with collective nouns, marks a relation of class inclusion - that is, of hyperonymy - for the two non-count plurals ${ }^{\mathrm{vi}}$.

\subsection{Additivity vs. non-additivity}

Another major difference between count collective nouns and furniture nouns is that the former are non-additive, that is, they are more than the sum of their parts (Gil, 1996, p. 63). For instance, John photographed the team differs from John photographed the players in that it adds the idea of a functional grouping: the players are part of the same functional set, have the same coach, will score together and not against one another, will be wearing the same outfits, etc. This is reflected in the scope of adjectives: for instance, a big team does not entail that each individual player is big. As indicated in the introduction, some collective nouns are more permeable than others, but all are partly non-additive. Furniture nouns, on the other hand, are additive. For instance, big furniture can only mean that each item is big.

As Joosten (2010, p. 43) himself notes, however, furniture nouns and count collective nouns share one conceptual characteristic: they do not primarily profile the individual entities. In this respect, they differ from pluralities (whether sums of individuals, e.g. the players, or coordinates, e.g. Mary and Peter), which identify the individuals directly. It could therefore be argued that furniture nouns and count collective nouns are just two subtypes of a class of collective nouns, which in any way is known to be heterogeneous (e.g. the nouns have

\footnotetext{
"Generative frameworks would use "DP", as the NP there is only one subpart of the DP. "NP" will be used here in a non-generative sense, focusing on the resulting surface phrase, as "NP" is more common outside generative approaches.

vi Another argument put forward by Lammert (2015, p. 78) is that French non-count plurals differ from collective nouns in that being non-count, they do not license cumulative reference using singular NPs: * $\underline{u n}$

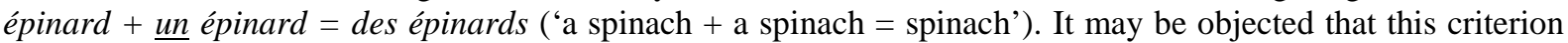
may not be a defining feature of collective nouns, all the more so as, as Lammert points out, cumulative reference with a plural gloss is acceptable $(\underline{\text { des }}$ épinards $+\underline{\text { des }}$ épinards $=$ des épinards $)$.
} 
different degrees of permeability, and nouns denoting inanimate collections do not license plural override).

\subsection{Contiguity vs. similarity}

In a collection, as denoted by a count collective noun, the units are related to each other by contiguity, whether spatio-temporal (e.g. archipelago), social (e.g. couple) or functional (e.g. pair [of shoes]). In other words, it is external factors that bring the units together. Conversely, with furniture nouns, the units are brought together because they share some basic properties; the furniture noun is a hyperonym, which means that the hyponyms inherit the properties it denotes. Hence a BE relation (which Joosten, 2010, p. 35, terms "kind of"): a chair Is furniture (vs. *an island is an archipelago).

Lammert (2010, p. 190), while acknowledging this difference, argues that the hyperonymic relation with furniture nouns is nevertheless of a specific kind, different from the taxonomic relation established between vehicle and car, and of a kind which brings furniture nouns close to count collective nouns. Namely, furniture nouns are strongly marked by diversity, and hence by a form of plurality. As shown by Wierzbicka (1988, p. 513), the superordinate category is "thought of as including a variety of things which can be used together." This intrinsic heterogeneity explains why the nouns are non-count: counting implies elements of the same kind - in addition to there being separate objects to be counted (ibid.). Also, although furniture can refer to a single item (a chair is furniture), in discourse the word is typically used for a plurality of items (e.g. the living-room furniture). This, again, is close to the characteristics of count collective nouns: for example, an archipelago is necessarily construed as being made up of several islands. Conversely, count superordinates (e.g. $a$ vehicle) do not share this characteristic. Consequently, only furniture nouns and count collective nouns can be used with non-distributive predicates, such as gather: the committee gathered / we gathered the furniture (vs. *we gathered the vehicle). I will add that this argument could be extended to belongings nouns, which necessarily have plural reference and also license non-distributive predicates (e.g. I gathered my belongings).

\section{4. "Part of" vs. "kind of" relations}

Joosten (2010) defines the relations between the whole and its parts, or between the hyperonym and its hyponyms, as follows:

- collective nouns (count), e.g. archipelago: [+ part of] [- kind of]

- aggregate nouns (non-count), e.g. furniture: [+ part of] [+ kind of]

- superordinate nouns (count only), e.g. vehicle: [- part of] [+ kind of]

In other words, collections have a [+ part of] [- kind of] relation between the whole and its members, whereas entities such as furniture have a [+ part of] [+ kind of] relation with the units. They are consequently between collections and superordinate categories, which have a [- part of] [+ kind of] relation with their hyponyms (e.g. a car is a kind of vehicle, but not *part of a vehicle).

While there is definitely a meronomic (part / whole) and hyperonymic (BE) relation with furniture nouns, I would not call the latter a "kind of" relation. Rather, I agree with Wierzbicka (1985, p. 322) in saying that ?a plate is a kind of crockery is odd compared to a rose is a kind of flower (or a car is a kind of vehicle). This is confirmed by a Google search of "kinds of crockery", which yields results such as delftware or crystal crockery, rather than plate $(s)$ or other objects - whereas "kinds of vehicles" yields nouns such as cars, trucks or mini-vans. In other words, both vehicle and furniture are hyperonyms, which means that their hyponyms inherit the properties they denote, but only vehicle is a taxonym, that is, a specific 
sub-type of hyperonym that is characterised by a "kind of" relation with its hyponyms (Cruse,

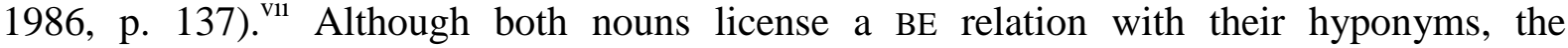
taxonymic hyperonym (e.g. vehicle) serves as an umbrella term for its hyponyms because they are seen as being of the same kind, whereas with furniture nouns, the units are brought together under the same umbrella term because they have a similar function (e.g. furniture) or because they are made of the same material (e.g. earthenware). But as indicated above, they are not construed as being of the same kind (Wierzbicka, 1988, p. 513). Consequently, Joosten's threefold distinction, while valid, does not necessarily mean that furniture nouns are as close to count superordinates as they are to count collective nouns.

Instead, they could be considered closer to count collective nouns, because of the "part of" relation they share. Indeed, count collective nouns (e.g. archipelago) have a meronomic, or "part of", or "part / whole" relationship with the nouns that denote the units that compose the whole (see also Cruse, 1986, p. 157). Hence the following glosses: an archipelago is composed of islands / islands can be part of an archipelago / an archipelago has islands (HAVE relation). Joosten (2010, p. 39) considers that the "part of" relation also holds for noncount singular nouns such as furniture, because a chair, for instance, is an item of furniture ${ }^{\text {viii }}$. In this respect, furniture nouns and count collective nouns differ from count superordinates, such as vehicle: *a vehicle is composed of cars and/or trucks / *a car is part of a vehicle /*a vehicle has cars.

\subsection{Set profiling vs. entity abstraction}

Finally, Joosten (2010, p. 43) shows that the motivations for using a count collective noun or a furniture noun are different. Use of the former is the result of "a strong conceptual focus on the newly-built unity", so that the individual entities are relegated to the background. This is a convincing argument: for groups of humans, for instance (e.g. committee, group), the anaphors can be it and which, which highlight the inanimate whole referred to. For furniture nouns, the aim of the superordinate is not so much to relegate the individual elements in the background as to relegate their specific identities, their differences. What is foregrounded is the shared properties, because it is them that are relevant in the context of communication. This is convincing as well. For instance, in the sentence The furniture comes with the house, it would not be relevant to itemise the tables, the chairs, the fridge, [etc.] because what matters in the context is the functional similarity between the elements. It could be added, though, that some collective nouns such as clergy, too, erase differences: the clergy is made up of priests, bishops, archbishops and so on.

Lammert (2010, p. 193) replies to Joosten that rather than have a narrow definition of collective nouns, and then various other classes of nouns that are very similar (such as "aggregates"), it would be more effective to have one broad class of "collective nouns", divided into sub-classes that share some additional characteristics. After all, everyone agrees that committee and forest are both collective nouns despite the fact that only the former can take plural verb agreement.

Such reasoning takes us one step further: should furniture and belongings nouns be included as well? This would be potentially useful for the description of meaning: just as count collective nouns are set apart from other count nouns (e.g. flower), furniture nouns would be set apart from other non-count nouns (e.g. water), and belongings nouns would be

\footnotetext{
vii Similarly, waiter is a hyponym, but not a taxonym, of man (*a waiter is a kind of man), as is stallion in relation to horse (? a stallion is a kind of horse).

viii Section 2.3. will reconsider this claim of a "part of" relation, which does not appear entirely satisfactory: neither have nor is part of, given as glosses of that relation, work for furniture nouns. E.g. *Furniture has tables and chairs, *A chair is part of furniture.
} 
set them apart from other non-count plurals which do not denote pluralities of units (e.g. measles, trousers). As was seen above, belongings nouns are not traditionally included among collective nouns, probably on the grounds that there is no discrepancy between a singular form and a plural denotation, but I agree with Lammert (2015) that this should not be viewed as a necessary condition: after all, non-count plurals are still nouns (rather than NPs) that denote pluralities of entities, and they, too, may have "part of" relations with the units (e.g. It's surprising how much of our belongings are made up of objects we don't really care for, COCA).

This is where a comparison with plural count nouns contributes to a better understanding of what hierarchies are established with furniture nouns, belongings nouns and count collectives. Section 2 now proposes a theoretical model based on that comparison.

\section{A theoretical model of sense relations for furniture nouns and belongings nouns}

\subsection{Starting point: proximity of furniture nouns with plural count nouns}

Although studies of the boundaries of collective nouns focus on the relationship between furniture nouns and count collectives in the singular (e.g. committee), it is a well-known fact that non-count nouns are close to plural count nouns (e.g. toys, vehicles). Here are the main established points of convergence, which are clearly relevant for furniture nouns (note that the first two also apply to collective nouns):

- (Acquaviva, 2008, p. 82) both non-count singular nouns and plural count nouns license nondistributive predicates, that is, predicates that apply to the whole group and not to each individual member considered separately. E.g. these toys fill the whole shelf (*each of these toys fills the whole shelf) / this furniture fills the whole room.

- (Murphy, 2010, p. 153) both furniture nouns and count plurals denote elements that have internal structure, that is, an entity that is made up of separate individuals. In this respect, furniture nouns differ from other non-count nouns such as mud.

- (Quine, 1960, pp. 90-100) both types have cumulative reference: toys + toys $=$ toys $/$ furniture + furniture $=$ furniture $(\mathrm{vs} . * a$ toy + a toy $=$ a toy). They also have the opposite property of divisibility (though not of arbitrary divisibility, as noted in the introduction): a subcollection of toys is still toys (similarly for furniture), whereas a part of a toy is not a toy. These two properties are due to the fact that neither count plurals nor furniture nouns denote bounded entities, contrary to singular count nouns (e.g. toy). ${ }^{\text {ix }}$

- (Radden \& Dirven, 2007, p. 68) there is a conceptual affinity between plurals (multiplex objects) and mass nouns: when one looks at a group of objects from a distance, they tend to shade into each other and therefore to appear as a mass. Cars, for example, become an unbounded, homogeneous flow of traffic. That is why both plural nouns and singular noncount nouns sometimes co-exist to express very similar realities: some varieties of pasta are viewed as countable objects (noodles), others as a mass (spaghetti); pebbles co-exists with gravel; etc.

- (Radden \& Dirven, 2007, p. 68, Langacker, 2008, p. 130) plural count nouns behave grammatically like non-count nouns: they do not license the indefinite article, the whole or an additional -s, and conversely they can take all, full of and can be used as bare nouns. Langacker concludes: "The mass noun category - in a broad sense of the term - includes both plurals and mass nouns 'proper'."

\footnotetext{
${ }^{\text {ix }}$ As regards cumulative reference (and similarly, divisibility) for collective nouns, it only applies if a merger is forced on the collective wholes. For instance, a bouquet + a bouquet may yield one big bouquet (but alternatively, may yield two bouquets). In this, collective nouns differ from count plurals and furniture nouns, for which cumulative reference applies whatever the circumstances.
} 
To these, the following additional points of convergence may be added:

- while a toy can be glossed as a car OR a castle OR a doll OR..., in the plural toys will be glossed as cars AND castles AND dolls AND... Similarly, furniture is glossed as chairs AND tables AND sideboards AND..., rather than a chair OR a table OR a sideboard OR...

- a study by Markman (1985) shows that when a picture of a couch on its own is presented to informants, it is identified as "a couch" much faster than as "furniture"; but that when the couch is shown as part of a living room scene, it is categorised equally fast as "furniture" and as "a couch". Markman concludes that presenting objects in groups aids superordinate classification. This could also be an indication that furniture nouns encode the idea of plurality.

- like plural count nouns, furniture nouns, even though they are non-count, license the adjective various: various furniture / jewelry / crockery / earthenware / confectionery / ammunition / ... This is not true of other singular non-count nouns (e.g. *various rice, *various gravel, *various water). The same applies to among. The idea of plural reference is therefore more salient with furniture nouns than with other non-count nouns.

- dictionary definitions of furniture nouns all have plural nouns as defining words. E.g. (OED 2015) "movable articles..." (furniture), "crocks or earthenware vessels..." (crockery), "gems or ornaments..." (jewelry), "clothes..." (menswear), "pots, dishes, and other objects..." (earthenware), etc.

- a look at furniture nouns in context, for instance via a Google search, shows that they are often found in alternation with plural count nouns. One example is nomenclatures of products. For instance, in Dogget et al. (1980)'s list of solid waste discards, one finds the following sample:

(1) * consumer and institutional products

097 - metal stampings

098 - cutlery, rand tools, hardware

147 - jewelry and silverware

148 - toys, sport, musical instruments

150 - misc. manufacturing, NEC

- finally, Murphy (2004, p. 227) points out that the common characteristics of elements brought together by superordinates (whether referred to with count or non-count nouns) are often abstract or functional. To him, "it seems likely that the abstract nature of superordinates is what encourages children to think of them as groups of objects". For instance, if children do not see at once what is common to all furniture (items vary widely in shape and specific function), they may tend to interpret furniture as referring to a collection of items. Perception of the common functional properties will come later, with greater experience and sophistication.

In sum, furniture nouns are particularly close to superordinate plural count nouns for three reasons:

- when they have plural reference, they denote several units (contrary to some other noncount nouns such as $m u d$ );

- they are non-count nouns and therefore denote unbounded wholes;

- they are superordinates.

From these three characteristics, they share a proximity to plural count nouns that other superordinates (e.g. singular vehicle) and other singular non-count nouns (e.g. mud) do not have. 
Based on these facts, the claim made here is that furniture nouns are superordinate hyperonyms of plural categories.

\subsection{Furniture nouns as hyperonyms of plural categories}

Saying that furniture nouns are superordinate hyperonyms of plural categories means that furniture, for instance, is best represented as (a), not as (b):

(a)

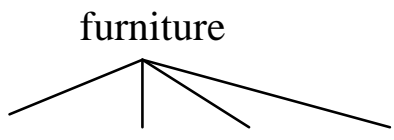

chairs tables sideboards ... (b)

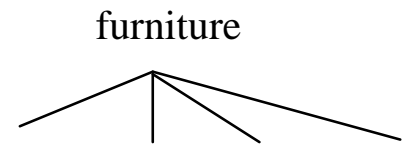

chair table sideboard ...

Although studies of hyperonomies tend to focus on singular nouns, the existence of plural categories is admitted. For instance, one commonly uses phrases such as "the class of determiners / nutrients / ..." (underlining mine, as in the remainder of this paper); or in his discussion of covert categories, Cruse (1986, p. 148) mentions the ad hoc category of "movable items one buys when moving into a new house: furniture (chairs, tables, beds, etc.),


cognitive linguistics, at least to my knowledge, seems to admit of both singulars and plurals in the naming of categories, without much theoretical difference. For instance, one reads:

(2) (Reed, 2012, p. 184) one characteristic of real-world, or natural, categories, is that they are hierarchical - some categories contain other categories. For example, the category furniture contains chairs, and the category chairs contains living-room chairs.

(3) (Ungerer \& Schmid, 2013, p. 179) Many words for superordinate categories do not belong to the simple one-syllable type which is dominant among basiclevel terms; this is true of FURNITURE, VEHICLE $\underline{S}$, MUSICAL INSTRUMENT $\underline{S}$, for instance. [While earlier on the page, also about superordinates, the authors mention the category TOY]

(4) (Radden \& Dirven, 2007, p. 70) [about the substance-object relation, one type of relation between the superordinate and basic levels of taxonomy:] substance

furniture

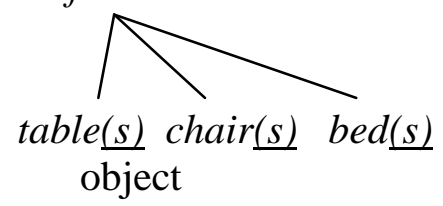

[...] Apart from furniture, this group includes the superordinate terms cutlery (BrE) or silverware (AmE) (and basic-level terms such as knives, forks and spoons), money (dollar, dime and cent), jewellery (ring_, bracelet_ and necklace_) and some others.

It could be argued at first sight that it does not matter whether the nouns are given in the singular or the plural: the plural denotes the class of occurrences, while the singular gives the name for the concept. For instance, Huddleston \& Pullum (2002, p. 335) write that boy denotes the class of boys - similarly, therefore, it could be said that the noun chair denotes the category CHAIR, which is also the category of chairs, and therefore that chair is a suitable 
hyponym for furniture, in the same way that car is a hyponym for another superordinate term, vehicle.

This, however, appears problematic for furniture nouns, because of the spontaneous tendency to have them denote a plurality of elements. In this sense, furniture does not function like vehicle. For instance, it seems difficult to say ??'Furniture can be a table or a chair or..." (vs. "A vehicle can be a car or a truck or..."). Besides, although a single chair can be accepted as "furniture", it will be more spontaneously described as "an item/a piece of furniture". See for instance this extract from a chapter on categorization:

(5) (Taylor, 2003, p. 24) A given entity may be categorized in many alternative ways. Chair, piece of furniture, artefact, and indeed, entity, are all equally true of naming the thing I am sitting on as I write this chapter.

The natural conclusion to be drawn from this type of description would therefore be that the direct hyperonym of chair is item of furniture, and not furniture. Which brings us back to the initial question: what are the hyponyms of furniture?

Considering that furniture nouns are superordinates of plural categories (that is, chairs, tables and so on) would explain why:

- furniture nouns are superordinates, yet are not used as defining terms in dictionary definitions. A refrigerator, for instance, is defined by the OED as "an appliance..." and not as "furniture...". Appliance is a hyperonym of refrigerator, whereas furniture is a hyperonym of refrigerators. Similarly, for chair, the OED uses "seat..." and not "furniture...". In the rare cases in which furniture is used in the definitions (e.g. for table), it is only in the form "item of furniture".

- furniture nouns often denote several items, especially of different kinds, yet can be used for a single item (e.g. a chair is furniture): as chairs is a hyponym of furniture, the category of chairs inherits the properties of furniture. Therefore, a single member of the category ( $a$ chair) also inherits these properties.

- a chair is furniture does not seem as fully spontaneous as, for instance, a refrigerator is an appliance. Appliance is a taxonomic hyperonym of refrigerator; furniture is only a "quasisuperordinate" of chair (Cruse, 1986, p. 97) ${ }^{\mathrm{x}}$. It is more precisely a superordinate of chairs.

- nouns such as jewel(s)/ jewelry co-exist: although they often denote the same reality (a number of jewels), they are not competitors. Jewel is a taxonomic hyperonym of ring, bracelet and so on, while jewelry is a hyperonym of rings, bracelets and so on.

This approach lays the foundations for concluding that furniture nouns, despite some similarities with collective nouns, belong to a different category. This is what section 2.3. now turns to.

\subsection{Furniture nouns are not collective nouns}

The similarities noted in the literature between furniture nouns and count collective nouns (e.g. committee) are in fact not specific to these two categories. They also hold for plural count nouns: these, too, denote pluralities of units and license non-distributive predicates. More importantly, the differences between the two sets of nouns also concern characteristics that furniture nouns share with plural count nouns. Here are the main ones:

\footnotetext{
' To Cruse (1986, p. 97), the notion of "quasi-superordinate" means that there is no X such that "It's a chair" and "It's a table" entail "It's an X". Furniture has "virtually the required meaning" for being a superordinate, but is "of the wrong syntactic category". I would add that this difference in grammar reflects a difference in conceptualisation.
} 
- boundedness vs. unboundedness: Lammert (2010) considers that furniture is close to count collective nouns because although it is non-count, it might be used in context for a bounded whole (e.g. my living-room furniture). But this is also true of plural NPs, for instance my toys; yet a plural NP is not a collective noun.

- additivity vs. non-additivity: both furniture nouns and plural NPs are additive, because they do not entail boundedness, whereas collective nouns are non-additive.

- similarity vs. contiguity: Lammert (2010) considers that the difference in conceptualisation between furniture nouns (similarity between the units) and count collective nouns (contiguity between the units) is not very significant: the BE relation is of a specific kind for furniture nouns, in the sense that furniture implies some sort of plurality, of heterogeneity. This is true, but it is also true of count superordinates used in the plural (e.g. vehicles is unlikely to be used just of cars).

- the gloss $X$ is composed of $Y s$, given by Cruse (1986, p. 157) as a typical gloss for meronomies, works very well for count collective nouns, but is difficult for furniture nouns and does not work at all for plural NPs. For instance, while an archipelago is composed of islands, a Google search for furniture is composed of... mostly yields material ${ }^{\mathrm{xi}}$ (and only sometimes units), and vehicles are composed of... could not yield units (*cars and trucks and...).

- about the "part of" and "kind of" relations, Joosten (2010) considers that collective nouns only exhibit a "part of" relation between the wholes and the members, while furniture shows both a "part of" and a "kind of" relation, and a count superordinate only a "kind of" relation. I propose to refine this as follows:

- first, Joosten's use of a common label "part of" for count collective nouns and furniture nouns can be misleading. While glosses such as a committee has members / an island can be part of an archipelago are possible, as noted above (section 1.4., footnote viii), they are not correct for furniture nouns: *furniture has tables and chairs /*a chair is part of furniture. ${ }^{\text {xii }}$

- $\quad$ rather, I would say that the relation between chairs and furniture is only BE, and that the "part of" impression is due to the fact that furniture is a superordinate of plural categories. Indeed, as Joosten notes in the same paper (2010, p. 31), if one adds the category/class of, a gloss in "part of" becomes possible for "kind of" relations: the category/class of birds is part of the category/class of animals - note the plural: birds, animals. Similarly, one could say that birds are part of (or even members of) the class of animals, and that chairs are part of (/members of) the class of furniture.

- another effect of the BE relation is that the units denoted by the hyponyms are construed as examples. For instance, a bird is an example of animal, as chairs are examples of furniture. This conceptualisation is totally impossible for count collective nouns: an island is not an example of archipelago.

- this analysis strengthens Joosten's argument that there is a fundamental difference in conceptualisation between collective nouns (contiguity) and furniture nouns (similarity). It also strengthens the notion that furniture nouns, in this respect, function like plural count superordinates (e.g. vehicles).

\footnotetext{
${ }^{x i}$ For instance: "Our outdoor furniture is composed of the heaviest available solid wrought iron stock with the best tubular steel to ensure strength and durability." (http://contractfurniture.com/resort/in-stockfurniture/connecticut/new-london/, 2015)

xii Note that in French, the equivalent of the first gloss is similarly unacceptable: *le mobilier a des tables et des chaises. For the second one (*a chair is part of furniture), the situation in French is more complex, due to a different value of the definite article ( $\underline{d u}$ mobilier) and to the existence of 'mediate anaphora' $(U n X, \underline{c a} . .$.$) in$ some cases of indefinite reference. Une chaise, ça fait partie du mobilier is acceptable, but only with ça. Further research bearing specifically on French would help to refine the analysis.
} 


\subsection{What differences between plural count nouns and furniture nouns?}

One difference between vehicles and furniture is that vehicles is count and formed by the addition of a plural feature to a singular base, while furniture is non-count. This reflects a difference in conceptualisation. Non-count nouns do not carry the [+bounded] feature, so that the boundaries between the individual units are backgrounded compared to an explicit plural morpheme.

This is particularly visible when the language has a pair of nouns that may apply to the same elements, but one of which is count, the other non-count; such as jewels / jewelry in English, or meubles / mobilier ('furniture') in French. About the French pair meubles / mobilier, Lammert (2014, pp. 92-97) shows that meubles is a taxonomic hyperonym identifying the nature of the object(s), whereas with mobilier, the perspective is that of a set of heterogeneous items, although all of them belong to a similar superordinate category (cf. meubles). The focus is on a common function, so that for instance, mobilier is disfavoured for random items of furniture, and preferred for items that together furnish a room.

In the pair jewels / jewelry, similarly, only jewels gives access to each individual unit:

- the anaphor is they, as opposed to it

- the units can be counted (in order to count, each individual unit has to be considered in turn), whereas *three jewelry is not grammatically correct. There would have to be three pieces/items of jewelry, with a twofold operation: counting (three pieces/items), and then only, giving the nature of the items (of jewelry).

In relation to this, as noted above, nouns such as jewelry are non-count because they bring together elements viewed as being of different kinds. It is therefore possible that when jewelry is used, heterogeneity of kinds might be more strongly expected than with jewels. For instance, it seems spontaneous to say that a ring is a jewel, two rings are two jewels, but that a ring and a bracelet are two jewels or two items of jewelry. A corpus-based study would establish whether this intuition can indeed be confirmed. Lammert (2014, p. 94) reaches a similar conclusion about French meubles / mobilier.

- jewels allows an anaphor that refers to an element that each individual item has (e.g. jewels more precious than their mountings suggested, COCA). This seems more difficult with jewelry (?jewelry more precious than its mountings suggested): because jewelry construes the jewels as an unbounded mass (the individual boundaries are backgrounded), the representation would be that of mountings here and there, rather than one mounting (or mountings) on each individual jewel.

- Chierchia (1998, p. 89) points out that plural count nouns license reciprocals, but furniture nouns do not. He takes the example of furniture: those pieces of furniture are leaning against each other vs. *that furniture is leaning against each other. This would also hold for jewels vs. jewelry.

In other words, although plural count nouns (e.g. jewels) and non-count singular nouns (e.g. jewelry) can be viewed as heading plural categories (jewels $=$ rings and bracelets and brooches..., jewelry $=$ rings and bracelets and brooches...), with plural count nouns, there is the idea of a sum of singulars, a sum of individual entities. The plural jewels is a taxonomic hyperonym of plural hyponyms (rings, bracelets and so on), and the singular jewel is similarly a superordinate for singular hyponyms (ring, bracelet and so on). The plural morpheme is just an addition to a base; a ring is a jewel, several rings are several jewels. Furniture nouns, on the other hand, do not profile individual items; they are only hyperonyms of plural categories, and often ${ }^{\text {xii }}$ there is no specific noun with the same root to head the

\footnotetext{
xiii One exception is jewel, as noted above. Other languages exhibit other occasional pairs; e.g. French meuble / mobilier.
} 
singular categories (e.g. for a chair or a table or a cupboard). To refer to a single object, one has to have a twofold operation (e.g. an item of furniture): a noun that denotes a bounded unit (item, piece), and a complement that denotes the nature of the unit (furniture).

The representation of hyperonymic relations with superordinate nouns could therefore be as follows:

(c)

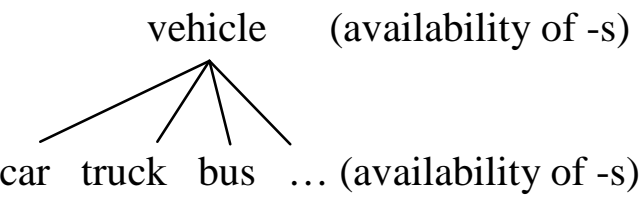

(d)

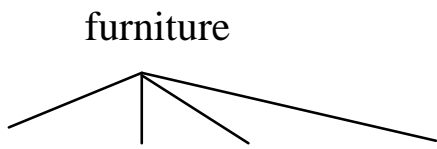

chairs tables sideboards ...

One question is whether to bring together vehicles and furniture under the same umbrella term. As noted in the introduction, one problem with this is that the question asks to compare an NP (vehicles) and a noun (furniture). In discourse, though, when both kinds of nouns are used in NPs, the reference is always (vehicles) or often (furniture) to several entities, so that the NPs are very close. Joosten's suggestion of aggregate nouns (and possibly, aggregate $N P s$ ) may seem a good candidate. Further research into the terminology, however, is required: the word aggregate noun is also applied by some, for instance, to sand or spinach (e.g. Vandeloise, 2007, p. 41), which are not of the same semantic category as furniture nouns. All that can be said here is that vehicle is a superordinate taxonomic hyperonym; that its plural vehicles denotes a plural category which is the result of a sum (understood as an addition of individual units); and that it is also a hyperonym of similarly obtained plural categories (cars, trucks, etc.); while furniture is a superordinate non-taxonomic hyperonym of plural categories, but not itself a sum.

\subsection{How do belongings nouns fit in?}

Belongings nouns, understood here as non-count plural nouns that denote several units, are of diverse morphology: some words in -ings (e.g. belongings, furnishings), -ana (e.g. breweriana, Victoriana), -ia (e.g. memorabilia, militaria), -ables (e.g. collectables, durables) or just isolated nouns (e.g. clothes, groceries). They are non-count (*one belonging, *two belongings), superordinate (for instance, it is impossible to draw a image that is representative of the whole category), but unlike furniture nouns, they take plural agreement. Some of them, especially nouns that denote units of a same domain (e.g. memorabilia, Victoriana), also license singular agreement, e.g. Sports memorabilia is highly collectible (COCA) - I will come back to this specificity below.

It can be said first that belongings nouns are clearly not collective nouns, because they do not denote a "part of" relation: *medals are part of militaria, *appliances are part of durables. Rather, they denote a BE relation: medals are militaria, appliances are durables. Other features they share with furniture nouns are additivity (old memorabilia, for instance, implies old objects) and an expected heterogeneity of kinds; moreover, dictionary definitions also use plural nouns as defining terms. For instance, memorabilia is defined as "Objects kept or collected..." (OED 2015).

Yet these nouns present two major differences with furniture nouns:

- they transparently indicate the shared feature in their morphology, hence what Acquaviva (2008, p. 104) terms a "whatever reading". For instance, durables are whatever products are durable, belongings are whatever belongs to someone, regalia are royalty-related objects. The units therefore do not necessarily share a quality; what matters is sometimes only a third party - e.g. an owner in the case of belongings, an era for Victoriana. 
Consequently, it seems more difficult sometimes to divide the units spontaneously into kinds. While militaria may be easily divided into weapons, helmets, medals and so on, memorabilia seems more difficult to circumscribe, and types of Victoriana returns no hits on Google. What seems to be profiled in the conceptualisation is the common feature denoted by the noun, with a whatever reading. This extreme diversity of kinds is reflected in the plural morphology of the nouns: a lexical plural (that is, a plural that is not compositional, but part of the base form of the word) means "not one", that is, foregrounds the idea of a non-simplex entity (Acquaviva, 2008).

- unlike furniture nouns, these nouns do not license piece(s) of / item(s) of: *pieces of belongings, *items of durables ${ }^{\mathrm{xiv}}$. The reason is probably related to their plural morphology, which profiles the multiplicity of units more highly than a singular would: similarly, items of is impossible with plural count nouns (*items of animals). Conversely, with furniture nouns, the singular foregrounds the erasure of individual boundaries, so that extraction of a bounded unit via a specific operation (item of) is compatible.

From these characteristics, I propose to conclude that belongings nouns, like furniture nouns, are superordinate terms that apply to a number of units, especially of different kinds. Some of them are also hyperonyms, e.g. durables, so that they may be representated as follows:

(e)



appliances garden equipment office furnishings ...

For some of these, it seems that a singular form and/or a singular agreement has become possible (e.g. durable, essential, eatable, and, as indicated above, nouns such as militaria). When the plural formed to derive the noun from the adjective is realised as an -s, the singular form denotes one object (e.g. a durable). When it is a Latin plural (e.g. militaria, regalia), the plural cannot be isolated, so that the singular noun, which is non-count, denotes an unbounded whole - thus bringing the noun into the class of furniture nouns, that is, of superordinate hyperonyms of plural categories.

For the other non-count plural nouns, it is much more difficult to come up spontaneously with subcategories. One extreme case is belongings, which the OED (2015) accordingly defines only as "Possessions, goods, effects". For these, I put forward the hypothesis that the speaker conceptualises the superordinate term as denoting several items of different kinds, rather than subcategories, and therefore that the nouns are superordinates, but not necessarily hyperonyms. This way of categorising would then be close to that of a category such as "movable items one buys when moving into a new house" mentioned above (borrowed from Cruse, 1986, p. 148). There would be two differences, though:

- the categories denoted by non-count plural nouns are not ad hoc categories,

- the nouns are non-count, so that the notion is not viewed just as a sum, the addition of individual entities of the same kind.

\section{Conclusion}

\footnotetext{
${ }^{\text {xiv }}$ The only terms that do license items or pieces are the nouns that denote items of a same domain (e.g. regalia, militaria, memorabilia), but as mentioned above, this is probably because they are then regarded as singular nouns.
} 
This paper has sought to show that existing approaches to collective nouns and furniture nouns, by focusing on singular nouns, have tended to propose a blurred view of the boundaries of the class of "collective nouns". They have put forward arguments for and against inclusion of furniture nouns, but ultimately, it was difficult to decide which were more legitimate. A new angle has therefore been proposed here, which also considers plural count nouns. This has shed light on a number of characteristics of furniture nouns, and in particular, shown that they are clearly not collective nouns. The concept of "superordinate hyperonym of plural categories" has been proposed instead. It has the advantage of solving all the problems noted in the literature. Another important point made thanks to this approach is that there is in fact no "part of" relation between a noun such as furniture and its hyponyms; there is only a $\mathrm{BE}$ relation, and it is the fact that the noun is a hyperonym of plural categories that accounts for the impression of a "part of" relation.

One major difference between furniture nouns and plural count nouns is that the former are nouns, and the latter NPs, the result of an addition of singularities. This has consequences on conceptualisation: only plural count nouns give total access to the units. The same applies to non-count plural nouns that denote units, here termed belongings nouns. These, too, are typically superordinates (some of them superordinate hyperonyms of plural categories) and do not allow full access to the units. They are not collective nouns either. The difference is one of lexical number (plural, as opposed to singular for furniture nouns), which again reflects a difference in conceptualisation. Belongings nouns foreground the multiplicity of units, so that items of cannot be added. Moreover, these nouns do not necessarily indicate a shared quality among their units; what brings them under the same umbrella term might be a third party (e.g. an era for Victoriana).

Finally, this study confirms a distinction proposed by Acquaviva (2008, pp. 101-105) between "cohesion" and "collectiveness": "the property of being related together [= cohesion] should not be confused with that of referring 'collectively' to one whole [= collectiveness]". Count collective nouns, furniture nouns and belongings nouns are all cohesive, but only count collective nouns, among those studied, are collective. At least two questions remain for further research. First, are collective nouns always count nouns; for instance, is foliage (which does not imply heterogeneity of kinds) a collective noun? Secondly, should furniture nouns and belongings nouns be termed aggregate nouns? Because some linguists use this label also for nouns such as sand or spinach, it was not chosen here. But a further study of labels for these nouns would lead to the selection of the most appropriate one.

\section{References}

Acquaviva, P. (2008). Lexical plurals : A morphosyntactic approach. Coll. Theoretical Linguistics. Oxford: Oxford University Press.

Arigne, V. (2005). Le syntagme N1 of N2 et la référence multiple des massifs anglais. Revue de sémantique et pragmatique 17, pp. 7-39.

Arigne, V. (2011). La figure du tout intégré et les noms discrets collectifs. Anglophonia 30, pp. 59-99.

Bache, C. (2002). On Categories in Linguistics. Acta Linguistica Hafniensia 34, pp. 71-105.

Chierchia, G. (1998). Plurality of mass nouns and the notion of "semantic parameter". In S. Rothstein (Ed.), Events and grammar (pp. 53-104). Dordrecht: Springer.

Corbett, G. (2006). Agreement. Cambridge textbooks in linguistics. Cambridge: Cambridge University Press.

The corpus of contemporary American English: 450 million words, 1990-present. Davies, M. 2008- . <http://corpus.byu.edu/coca/>

Cruse, D. A. (1986). Lexical semantics. Cambridge: Cambridge University Press. 
Dogget, R. M. et al. (1980). Forecasts of the quantity and composition of solid waste. University of Michigan: Research Reporting Series.

Flaux, N. (1999). A propos des noms collectifs. Revue de linguistique romane $\mathrm{n}^{\circ} 251-252$, tome 63, pp. 471-502.

Flaux, N. \& Van de Velde, D. (2000). Les noms en français : esquisse de classement. Paris: Ophrys.

Gil, D. (1996). Maltese "collective nouns": A typological perspective. Rivista di Linguistica 8:1, pp. 53-87.

Greenbaum, S. (1996). The Oxford English grammar. Oxford: Oxford University Press.

Huddleston, R. \& Pullum, G. K. (2002). The Cambridge grammar of the English language. Cambridge: Cambridge University Press.

Jackendoff, R. (1991). Parts and boundaries. In B. Levin, \& S. Pinker (Eds.), Lexical and conceptual semantics (pp. 9-45). Cambridge: Blackwell.

Jackendoff, R. (2012). Language as a source of evidence for theories of spatial representation. Perception 41, pp. 1128-1152.

Joosten, F. (2006). Why club and lingerie do not belong together. A plea for redefining collective nouns. In G. Kleiber et al. (Eds.), La relation partie-tout (pp. 73-88). Paris: Peeters.

Joosten, F. (2010). Collective nouns, aggregate nouns, and superordinates: when "part of" and "kind of" meet. Linguisticae Investigationes 33:1, pp. 25-49.

Joosten, Frank et al. (2007). Dutch collective nouns and conceptual profiling. Linguistics 45:1, pp. 85-132.

<http://eprints.soton.ac.uk/144837/1/Joosten,_De_Sutter,_Drieghe_et_al._(2007) .pdf $>$

Kirkby, J. (1971 [1746]). A new English grammar. Menton: Scolar Press.

Lammert, M. (2010). Sémantique et cognition: Les noms collectifs. Geneva: Droz.

Lammert, M. (2014). Référence collective massive vs. référence plurielle indéfinie. Langue française 183, pp. 87-99.

Lammert, M. (2015). Les pluralia tantum sous l'angle du collectif. Langue française 185, pp. 73-84.

Langacker, R. W. (2008). Cognitive grammar: A basic introduction. Oxford: Oxford University Press.

Markman, E. M. (1985). Why superordinate category terms can be mass nouns. Cognition 19, pp. 31-53.

Murphy, G. L. (2004 [2002]). The big book of concepts. Cambridge, MA: MIT Press.

Murphy, L. (2010). Lexical meaning. Cambridge: Cambridge University Press.

Oxford English dictionary, online edition (2014). Oxford: Oxford University Press.

Quine, W. Van Orman (1960). Word and object. Cambridge, MA: MIT Press.

Radden, G. \& Dirven, R. (2007). Cognitive English grammar. Amsterdam: John Benjamins.

Reed, S. K. (2012). Cognitive theories and applications, $9^{\text {th }}$ edition. Belmont, USA: Wadsworth.

Taylor, J. R. (2003). Linguistic categorization, $3^{\text {rd }}$ edition. Oxford textbooks in linguistics. Oxford: Oxford University Press.

Ungerer, F., \& Schmid H.-J. (2013). An introduction to cognitive linguistics, $2^{\text {nd }}$ edition. London: Routledge.

Vandeloise, C. (2007). A taxonomy of basic natural entities. In Michel Aurnague, Maya Hickmann and Laure Vieu (eds.), The categorization of spatial entities in language and cognition (pp. 35-52). Amsterdam: John Benjamins. 
Wierzbicka, A. (1985). Oats and wheat: the fallacy of arbitrariness. In J. Haiman (Ed.), Typological Studies in Langage vol. 6: Iconicity in Syntax (pp. 311-342). Amsterdam: John Benjamins.

Wierzbicka, A. (1988). The semantics of grammar. Amsterdam: John Benjamins. 